\title{
Synthesis of lipophilic tyrosyl esters derivatives and assessment of their antimicrobial and antileishmania activities
}

\author{
Imen Aissa ${ }^{1,3}$, Rabiaa Manel Sghair ${ }^{2}$, Mohamed Bouaziz ${ }^{3}$, Dhafer Laouini², Sami Sayadi ${ }^{3}$ and Youssef Gargouri ${ }^{1 *}$
}

\begin{abstract}
Background: Preparation of tyrosyl lipophilic derivatives was carried out as a response to the food, cosmetic and pharmaceutical industries' increasing demand for new lipophilic antioxidants.

Results: A large series of tyrosyl esters $\left(T_{y} C_{2}\right.$ to $\left.\mathbf{T y C}_{18: 1}\right)$ with increasing lipophilicity was synthesized in a good yield using lipase from Candida antarctica (Novozyme 435). Spectroscopic analyses of purified esters showed that the tyrosol was esterified on the primary hydroxyl group. Synthetized compounds were evaluated for either their antimicrobial activity, by both diffusion well and minimal inhibition concentration (MIC) methods, or their antileishmanial activity against Leishmania major and Leishmania infantum parasite species. Among all the tested compounds, our results showed that only $\mathbf{T y C}_{\mathbf{8}}, \mathbf{T y} \mathbf{C}_{10}$ and $\mathbf{T y C}_{12}$ exhibited antibacterial and antileishmanial activities. When MIC and $I_{50}$ values were plotted against the acyl chain length of each tyrosyl derivative, $\mathbf{T y C}_{10}$ showed a parabolic shape with a minimum value. This nonlinear dependency with the increase of the chain length indicates that biological activities are probably associated to the surfactant effectiveness of lipophilic derivatives.
\end{abstract}

Conclusion: These results open up potential applications to use medium tyrosyl derivatives surfactants, antioxidants, antimicrobial and antileishmanial compounds in cosmetic, food and pharmaceutical industries.

Keywords: Tyrosol, antioxidant, antimicrobial activity, leishmanicidal activity

\section{Background}

Polyphenolic compounds produced by plants are of considerable interest, both as functional food ingredients and as nutraceuticals [1]. In addition to their antioxidant properties, several studies showed that phenolic compounds also have antimicrobial properties by denaturing proteins and inactivating enzymes [2,3]. Tyrosol [2-(4-hydroxyphenyl) ethanol] is a well-known monophenolic antioxidant present in large amount in olive oil and can be extracted from olive mill waste water [4]. Its efficiency was demonstrated in inhibiting the oxidation of cholesterol in LDL and preventing the modification of the apoproteic moiety [5]. Tyrosol has been also effective in inhibiting leukocyte 5-lipooxygenase [6] and protecting the Caco-2 intestinal

\footnotetext{
* Correspondence: ytgargouri@yahoo.fr

'Laboratoire de Biochimie et de Génie Enzymatique des Lipases, Ecole Nationale d'Ingénieurs de Sfax (ENIS). Route de Soukra, BP 1173, 3038 Sfax, Université de Sfax,Tunisie

Full list of author information is available at the end of the article
}

mucosa cells against the cytostatic and cytotoxic effects produced by oxidized LDL [7]. Many other activities of tyrosol were described such as its ability to inhibit ADPinduced platelet aggregation [8], to significantly reduce the arrhythmic activity that occurs during myocardial ischemia and reperfusion [9], and to possess significant neuroprotective activities against glutamate-induced neurotoxicity in primary cultures of rat cortical cells and injury induced by 5 -S-cysteinyl-dopamine in vitro [10]. Hence, lipophilic derivatives of tyrosol and, in particular, esters bearing acyl chains, exhibit a better affinity with lipophilic membrane constituents. For this reason and others, these compounds could be important for further application in pharmaceutical and cosmetic fields [11]. Some tyrosyl derivatives have been found in diverse natural sources e.g., the presence of its acetate was reported in virgin olive oil [12], and its lipophilic palmitate, stearate, and oleate esters were isolated from Ligustrum ovalifolium flowers [13], from the stem
C Biomed Central

() 2012 Aissa et al; licensee BioMed Central Ltd. This is an Open Access article distributed under the terms of the Creative Commons Attribution License (http://creativecommons.org/licenses/by/2.0), which permits unrestricted use, distribution, and reproduction in any medium, provided the original work is properly cited. 
bark of Buddleja cordata [14], and from olive fruits [15], respectively. In addition, the use of some natural tyrosyl esters for antiaging and/or pharmacological applications has been of attracting interest in the past few years [16]. For all these reasons, growing attention has been devoted to the synthesis of tyrosyl esters derived from fatty acids. Short, medium and long chain derivatives of the tyrosol were synthesized by trans-esterification reactions using lipases $[17,18]$. Amphiphilic tyrosol derivatives display particularly interesting characteristics, resulting from the modification of molecular flexibility. The evaluation of antioxidant activity using Rancimat, FRAP and ABTS methods showed that tyrosyl esters are less active than free tyrosol [18]. Few data regarding the biological activities of tyrosyl esters have been reported. Fragoupoulou et al, [11] have shown that the monoacetylated tyrosol is two orders of magnitude more potent as anti-thrombic agent than tyrosol, and Ahn et al, [19] have reported that p-tyrosyl acetate reduces the cell viability of some cancer cell types better than tyrosol. Singh et al, [20] have synthesized several piperoyl-amino acides ester conjugates (chemical derivatives of alkaloid piperine) and have evaluated their antileishmanial activity in vitro and in vivo. They found that piperoyl-valine methyl ester showed the best activity against the amastigotes and a reduction of $24 \%$ in spleen parasitic burden in vivo assay with golden hamsters. However, there is no data, in the literature, showing the antileishmanial activity of tyrosyl esters derivatives.

In this purpose, we have synthetized a large series of tyrosyl fatty acid esters by direct esterification of tyrosol with different fatty acids using Novozyme 435 as catalyst and evaluated their anti-microbial activity against several pathogenic strains and their anti-leishmanial effects on both Leishmania $(L)$ major and L. infantum strains.

\section{Results}

\section{Preparation and Characterization of Tyrosyl Esters}

A chemoselective procedure was used to synthetize lipophilic tyrosyl esters $\left(\mathbf{T y C}_{\mathbf{2}}\right.$ to $\left.\mathbf{T y} \mathbf{C}_{\mathbf{1 8 : 1}}\right)$ (Figure 1). Lipase from $C$. antarctica has been used as a catalyst for the esterification reactions. The conversion yields calculated after $72 \mathrm{~h}$ are respectively: $\mathbf{T y C}_{2}: 99.74 \%, \mathbf{T y C}_{3}: 95.93 \%$, $\mathrm{TyC}_{\mathbf{8}}: 85.55 \%, \mathbf{T y C}_{\mathbf{1 0}}: 75.42 \%, \mathbf{T y C}_{\mathbf{1 2}}: 73.33 \%, \mathbf{T y C}_{\mathbf{1 6}}$ : 69.95\%, $\mathbf{T y C}_{18}: 66.95 \%$ and $\mathrm{TyC}_{18: 1}: 57 \%$. As shown, highest ester synthesis yields were obtained when using short acyl chains ester $\left(\mathbf{T y C}_{2}\right.$ and $\left.\mathbf{T y} \mathbf{C}_{3}\right)$. For medium and long chain esters $\left(\mathrm{TyC}_{\mathbf{8}}\right.$ to $\left.\mathbf{T y C}_{\mathbf{1 8 : 1}}\right)$, the conversion yield decrease with the increasing of the acyl chain length. The same results were obtained by Mateos et al, [18] for the synthesis of tyrosyl esters by a transesterifcation reaction, but the rate of the reaction is higher than the esterification procedure. This can be attributed to water production during the esterification reaction, which can promote the hydrolysis of formed ester. However, during the transesterification reaction, the reaction temperature favorites the elimination of methanol, produced as co product, by evaporation. This kind of process can contribute to shift the reaction equilibrium to the synthesis of ester [21].

The fatty acid unsaturation seems to affect the synthesis yield. In fact, the conversion yield obtained with the tyrosyl stearate, $66.95 \%$; decreases to $57 \%$ when using the oleic acid to synthesize the tyrosyl oleate. Our observations are in agreement with those described by Selmi et al. [22] when synthesizing several triacylglycerol esters using immobilized Rhizomucor miehei lipase. These authors concluded that the increase of the unsaturation number is responsible for the lower rate of triacylglycerols synthesis [22].

Tyrosyl esters were characterized by NMR. As shown in Table 1 there are differences of 0.61 and $0.21 \mathrm{ppm}$, respectively, for the chemical shifts $(\delta)$ of $\mathrm{H}_{1}$ and $\mathrm{H}_{2}$ with respect to the same values in free tyrosol. For the aromatic protons, these differences are very weak but still appreciable $(0.03$ and $0.08 \mathrm{ppm})$. Similar deshielding effects can be observed from ${ }^{13} \mathrm{C}$ data (Table 2), although the expected $\beta$-shielding effect is evident for $C_{2}$ in each ester.

\section{Antimicrobial activity of tyrosyl derivatives}

Tyrosol and its esters were investigated for their antimicrobial activity against several pathogenenic bacteria spp. Tyrosol showed no inhibition against all the

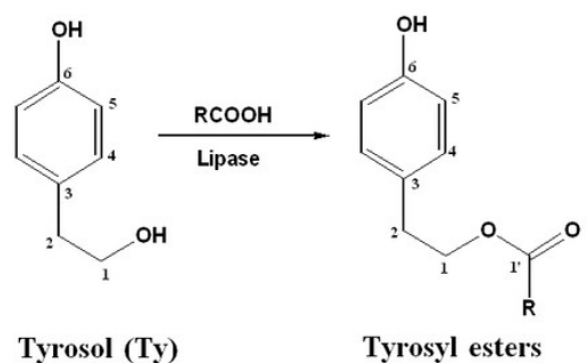

\begin{tabular}{llc}
\hline \multicolumn{2}{c}{ Tyrosyl esters } & $\mathrm{R}$ \\
\hline Tyrosyl acetate & $\left(\mathrm{TyC}_{2}\right)$ & $-\mathrm{CH}_{3}$ \\
Tyrosyl propionate & $\left(\mathrm{TyC}_{3}\right)$ & $-\mathrm{C}_{2} \mathrm{H}_{5}$ \\
Tyrosyl caprylate & $\left(\mathrm{TyC}_{8}\right)$ & $-\mathrm{C}_{7} \mathrm{H}_{15}$ \\
Tyrosyl capriate & $\left(\mathrm{TyC}_{10}\right)$ & $-\mathrm{C}_{9} \mathrm{H}_{19}$ \\
Tyrosyl laurate & $\left(\mathrm{TyC}_{12}\right)$ & $-\mathrm{C}_{11} \mathrm{H}_{23}$ \\
Tyrosyl palmitate & $\left(\mathrm{TyC}_{16}\right)$ & $-\mathrm{C}_{15} \mathrm{H}_{31}$ \\
Tyrosyl stearate & $\left(\mathrm{TyC}_{18}\right)$ & $-\mathrm{C}_{17} \mathrm{H}_{35}$ \\
Tyrosyl oleate & $\left(\mathrm{TyC}_{18: 1}\right)$ & $-\mathrm{C}_{17} \mathrm{H}_{33}$ \\
\hline & &
\end{tabular}

Figure 1 Structure of Synthesized Compounds 
Table $1{ }^{1} \mathrm{H}$ NMR Data (300 $\mathbf{M H z}, \mathrm{CDCL}_{3}$ ) for Compounds Ty to $\mathrm{TyC}_{18: 1}$

\begin{tabular}{|c|c|c|c|c|c|c|c|c|c|}
\hline & (Ty) & $\left(\mathrm{TyC}_{2}\right)$ & $\left(\mathrm{TyC}_{3}\right)$ & $\left(\mathrm{TyC}_{8}\right)$ & $\left(\mathrm{TyC}_{10}\right)$ & $\left(\mathrm{TyC}_{12}\right)$ & $\left(\mathrm{TyC}_{16}\right)$ & $\left(\mathrm{TyC}_{18}\right)$ & $\left(\mathrm{TyC}_{18: 1}\right)$ \\
\hline 1 & $3.72(\mathrm{t})$ & $4.26(\mathrm{t})$ & $4.26(\mathrm{t})$ & $4.28(\mathrm{t})$ & $4.24(\mathrm{t})$ & $4.25(\mathrm{t})$ & $4.31(\mathrm{t})$ & $4.23(t)$ & $4.23(\mathrm{t})$ \\
\hline 2 & $2.71(\mathrm{t})$ & $2.87(\mathrm{t})$ & $2.87(\mathrm{t})$ & $2.87(\mathrm{t})$ & $2.85(\mathrm{t})$ & $2.85(\mathrm{t})$ & $2.92(\mathrm{t})$ & $2.85(\mathrm{t})$ & $2.82(\mathrm{t})$ \\
\hline 4 & $\begin{array}{l}7.11(\mathrm{~d}) \\
J_{4,5}=8.4\end{array}$ & $\begin{array}{l}7.10(d) \\
J_{4,5}=8.4\end{array}$ & $\begin{array}{l}7.07(d) \\
J_{4,5}=8.4\end{array}$ & $\begin{array}{l}7.08(\mathrm{~d}) \\
\mathrm{J}_{4,5}=8.4\end{array}$ & $\begin{array}{l}7.06(d) \\
J_{4,5}=8.4\end{array}$ & $\begin{array}{l}7.04(d) \\
J_{4,5}=8.4\end{array}$ & $\begin{array}{l}7.12(\mathrm{~d}) \\
\mathrm{J}_{4,5}=8.4\end{array}$ & $\begin{array}{l}7.07(d) \\
J_{4,5}=8.4\end{array}$ & $\begin{array}{l}7.09(d) \\
J_{4,5}=8.4\end{array}$ \\
\hline 5 & $\begin{array}{l}6.79(d) \\
J_{4,5}=9\end{array}$ & $\begin{array}{l}6.80(d) \\
J_{4,5}=9\end{array}$ & $\begin{array}{l}6.80(\mathrm{~d}) \\
\mathrm{J}_{4,5}=9\end{array}$ & $\begin{array}{l}6.80(\mathrm{~d}) \\
J_{4,5}=9\end{array}$ & $\begin{array}{c}6.79 \\
J_{4,5}=9\end{array}$ & $\begin{array}{l}6.80(d) \\
J_{4,5}=9\end{array}$ & $\begin{array}{c}6.80(d) \\
J_{4,5}=9\end{array}$ & $\begin{array}{l}6.80(d) \\
J_{4,5}=9\end{array}$ & $\begin{array}{l}6.80(d) \\
J_{4,5}=9\end{array}$ \\
\hline 6 & & $5.50(\mathrm{~s})$ & $5.50(\mathrm{~s})$ & $5.50(\mathrm{~s})$ & $5.50(\mathrm{~s})$ & $5.50(\mathrm{~s})$ & $6.00(\mathrm{~s})$ & $5.10(\mathrm{~s})$ & $5.30(\mathrm{~s})$ \\
\hline $2^{\prime}$ & & $2.06(\mathrm{~s})$ & $2.32(\mathrm{q})$ & $2.33(\mathrm{t})$ & $2.29(\mathrm{t})$ & $2.30(\mathrm{t})$ & $2.36(t)$ & $2.30(\mathrm{t})$ & $2.30(\mathrm{t})$ \\
\hline $3^{\prime}$ & & & $1.13(\mathrm{t})$ & $1.60(\mathrm{~m})$ & $1.59(\mathrm{~m})$ & $1.60(\mathrm{~m})$ & $1.66(\mathrm{~m})$ & $1.60(\mathrm{~m})$ & $1.60(\mathrm{~m})$ \\
\hline $4^{\prime}$ & & & & $1.28(\mathrm{~m})$ & $1.25(\mathrm{~m})$ & $1.26(\mathrm{~m})$ & $1.32(\mathrm{~m})$ & $1.25(\mathrm{~m})$ & $1.25(\mathrm{~m})$ \\
\hline$\left(\mathrm{CH}_{2}\right)_{3}$ & & & & $1.28(\mathrm{~m})$ & $1.25(\mathrm{~m})$ & $1.26(\mathrm{~m})$ & $1.32(\mathrm{~m})$ & $1.25(\mathrm{~m})$ & $1.25(\mathrm{~m})$ \\
\hline $8^{\prime}$ & & & & $0.9(\mathrm{t})$ & $1.25(\mathrm{~m})$ & $1.26(\mathrm{~m})$ & $1.32(\mathrm{~m})$ & $1.25(\mathrm{~m})$ & $2.00(\mathrm{~m})$ \\
\hline $9^{\prime}$ & & & & & $1.25(\mathrm{~m})$ & $1.26(\mathrm{~m})$ & $1.32(\mathrm{~m})$ & $1.25(\mathrm{~m})$ & $5.33(\mathrm{~m})$ \\
\hline $10^{\prime}$ & & & & & $0.88(\mathrm{t})$ & $1.26(\mathrm{~m})$ & $1.32(\mathrm{~m})$ & $1.25(\mathrm{~m})$ & $5.33(\mathrm{~m})$ \\
\hline $11^{\prime}$ & & & & & & $1.26(\mathrm{~m})$ & $1.32(\mathrm{~m})$ & $1.25(\mathrm{~m})$ & $2.00(\mathrm{~m})$ \\
\hline $12^{\prime}$ & & & & & & $0.88(\mathrm{t})$ & $1.32(\mathrm{~m})$ & $1.25(\mathrm{~m})$ & $1.25(\mathrm{~m})$ \\
\hline $13^{\prime}$ & & & & & & & $1.32(\mathrm{~m})$ & $1.25(\mathrm{~m})$ & $1.25(\mathrm{~m})$ \\
\hline $14^{\prime}$ & & & & & & & $1.32(\mathrm{~m})$ & $1.25(\mathrm{~m})$ & $1.25(\mathrm{~m})$ \\
\hline$\left(\mathrm{CH}_{2}\right)_{\mathrm{n}}$ & & & & & & & $1.32(\mathrm{~m})$ & $1.25(\mathrm{~m})$ & $1.25(\mathrm{~m})$ \\
\hline $\mathrm{Me}$ & & & & & & & $0.94(\mathrm{t})$ & $0.87(\mathrm{t})$ & $0.87(\mathrm{t})$ \\
\hline
\end{tabular}

bacteria tested in this study (Table 3). Among all esters tested, only medium chain tyrosyl derivatives $\left(\mathbf{T y C}_{\mathbf{8}}\right.$, $\mathbf{T y C}_{\mathbf{1 0}}$ and $\mathbf{T y C}_{\mathbf{1 2}}$ ) exhibited an antibacterial activity. Hence, at $20 \mathrm{mg} / \mathrm{ml}, \mathbf{T y C}_{\mathbf{8}}$ and $\mathbf{T} \mathbf{y} \mathbf{C}_{\mathbf{1 0}}$ showed the highest inhibitory activity against $S$. aureus, S. xylosus, B. cereus and $B$. flavum whereas tyrosyl laurate $\left(\mathbf{T y C}_{\mathbf{1 2}}\right)$ exhibited the lowest antimicrobial activity against Staphylococcus strains.

The minimum inhibition concentration (MIC) of Tyrosol, $\mathbf{T y C}_{\mathbf{8}}, \mathbf{T y C}_{\mathbf{1 0}}$ and $\mathbf{T y C}_{\mathbf{1 2}}$ for S. aureus, S. xylosus and $B$. cereus was also investigated. Table 4 shows that $\mathbf{T} \mathbf{y} \mathbf{C}_{\mathbf{1 0}}$ has the most potent effect. It exhibits the lowest MIC values towards the three tested strains $(3.12 \mu \mathrm{g} / \mathrm{ml}$ against $B$. cereus, and $12.5 \mu \mathrm{g} / \mathrm{ml}$ against staphylococcus strains). The obtained MIC values of $\mathbf{T y C}_{\mathbf{8}}$ were $12.5 \mu \mathrm{g} /$ $\mathrm{ml}$ against $B$. cereus and $25 \mu \mathrm{g} / \mathrm{ml}$ against staphylococcus strains, while MIC values of $\mathbf{T} \mathbf{y} \mathbf{C}_{\mathbf{1 2}}$ were estimated to more than $50 \mu \mathrm{g} / \mathrm{ml}$ against the three strains. Finally, Ty does not exhibit any antimicrobial effect up to $5 \mathrm{mg} / \mathrm{ml}$.

\section{Antileishmanial activity}

Tyrosol and its lipophilic derivatives were screened for their leishmanicidal activity. The screening was carried out using two Leishmania species: L. major GLC94 [23] and L. infantum LV50 [24]. As shown in Table 5 only three tyrosyl derivatives $\mathbf{T y C}_{\mathbf{8}}, \mathbf{T y} \mathbf{C}_{\mathbf{1 0}}$ and $\mathbf{T} \mathbf{y} \mathbf{C}_{\mathbf{1 2}}$ were effective against both Leishmania species while either tyrosol or short and long chain derivatives have no leishmanicidal activity. Interestingly, the three effective derivatives showed a higher activity against the $L$. major promastigotes compared to that obtained against $L$. infantum promastigote. Indeed, $\mathrm{IC}_{50}$ values were approximately two times higher against the former than the later. This indicates that L. major parasites are more sensitive to these compounds than L. infantum ones. The most effective compound is $\mathbf{T y C}_{\mathbf{1 0}}$ which showed an $\mathrm{IC}_{50}$ of $19.21 \mu \mathrm{g} / \mathrm{ml}$ and $38.73 \mu \mathrm{g} / \mathrm{ml}$ against L. major and $L$. infantum respectively. On the other hand, $\mathbf{T y}_{\mathbf{8}}$ showed a moderate activity of $38.09 \mu \mathrm{g} / \mathrm{ml}$ and $62.8 \mu \mathrm{g} /$ $\mathrm{ml}$ against $L$. major and $L$. infantum respectively. Finally, $\mathrm{TyC}_{12}$ was the less active compound of the three derivatives which showed an $\mathrm{IC}_{50}$ of $60.34 \mu \mathrm{g} / \mathrm{ml}$ and 157.6 $\mu \mathrm{g} / \mathrm{ml}$ against the dermotropic and the visceraotropic spp respectively.

\section{Discussion}

The biological activity of the lipophilic tyrosyl derivatives is at yet not well understood. After tyrosyl fatty acid ester derivatives production by a chemoselective enzymatic esterification of tyrosol we investigated in this study, and for the first time, the relationship of the carbon number of these tyrosyl derivatives and their antimicrobial and antileishmanial activities.

As showed in Figure 2, when MIC and $\mathrm{IC}_{50}$ values are plotted against the acyl chain length for the tyrosyl derivatives, a parabolic shape with a maximum of 10 carbon atoms $\left(\mathbf{T} \mathbf{y} \mathbf{C}_{\mathbf{1 0}}\right)$ can be observed. This effect is probably due the surfactant effectiveness of the derivatives. 
Table $2{ }^{13} \mathrm{C}$ NMR Chemical Shifts (ppm) (125

\begin{tabular}{|c|c|c|c|c|c|c|c|c|c|}
\hline & (Ty) & $\left(\mathrm{TyC}_{2}\right)$ & $\left(\mathrm{TyC}_{3}\right)$ & $\left(\mathrm{TyC}_{8}\right)$ & $\left(\mathrm{TyC}_{10}\right)$ & $\left(\mathrm{TyC}_{12}\right)$ & $\left(\mathrm{TyC}_{16}\right)$ & $\left(\mathrm{TyC}_{18}\right)$ & $\left(\mathrm{TyC}_{18: 1}\right)$ \\
\hline 1 & 63.1 & 65.7 & 65.6 & 65.9 & 65.3 & 63.7 & 65.6 & 65.6 & 65.7 \\
\hline 2 & 37.2 & 34.6 & 34.6 & 34.6 & 34.4 & 32.7 & 34.8 & 34.8 & 35.0 \\
\hline 3 & 130.6 & 130.2 & 130.12 & 129.6 & 129.9 & 127.5 & 129.9 & 129.9 & 130.9 \\
\hline 4 & 131.3 & 130.4 & 130.41 & 130.3 & 129.4 & 128.2 & 130.3 & 130.3 & 130.07 \\
\hline 5 & 115.7 & 115.8 & 115.7 & 115.9 & 115.4 & 113.7 & 115.7 & 115.7 & 116.1 \\
\hline 6 & 154.1 & 154.8 & 154.8 & 155.2 & 154.7 & 153.1 & 154.9 & 154.9 & 155.4 \\
\hline $1^{\prime}$ & & 171.9 & 174.1 & 175.4 & 174.7 & 173.1 & 174.9 & 174.4 & 174.6 \\
\hline $2^{\prime}$ & & 21.4 & 30.09 & 34.8 & 34.3 & 32.7 & 34.6 & 34.6 & 32.6 \\
\hline $3^{\prime}$ & & & 28.04 & 25.3 & 31.9 & 23.2 & 25.3 & 25.34 & 25.7 \\
\hline $4^{\prime}$ & & & & $29.4-29.2$ & $29.4-29.1$ & $27.9-27.4$ & $29.5-30.1$ & $29.5-30.1$ & $29.8-28.0$ \\
\hline$\overline{\left(\mathrm{CH}_{2}\right)_{3}}$ & & & & $29.4-29.2$ & $29.4-29.1$ & $27.9-27.4$ & $29.5-30.1$ & $29.5-30.1$ & $29.8-28.0$ \\
\hline $8^{\prime}$ & & & & 14.4 & 24.8 & $27.9-27.4$ & $29.5-30.1$ & $29.5-30.1$ & 27.2 \\
\hline $9^{\prime}$ & & & & & 22.6 & $27.9-27.4$ & $29.5-30.1$ & $29.5-30.1$ & 129.8 \\
\hline $10^{\prime}$ & & & & & 14.1 & 32.5 & $29.5-30.1$ & $29.5-30.1$ & 128.0 \\
\hline $11^{\prime}$ & & & & & & 21.0 & $29.5-30.1$ & $29.5-30.1$ & 27.2 \\
\hline $12^{\prime}$ & & & & & & 12.43 & $29.5-30.1$ & $29.5-30.1$ & $29.8-28.0$ \\
\hline $13^{\prime}$ & & & & & & & $29.5-30.1$ & $29.5-30.1$ & 29.8-28.0 \\
\hline $14^{\prime}$ & & & & & & & 32.3 & $29.5-30.1$ & $29.8-28.0$ \\
\hline $15^{\prime}$ & & & & & & & 23.1 & $29.5-30.1$ & $29.8-28.0$ \\
\hline $16^{\prime}$ & & & & & & & 14.5 & 32.3 & 31.9 \\
\hline $17^{\prime}$ & & & & & & & & 23.09 & 23.4 \\
\hline$\overline{18^{\prime}}$ & & & & & & & & 14.5 & 14.8 \\
\hline
\end{tabular}

Indeed, Lucas et al, [25] have observed in emulsion system that when the surfactant effectiveness is plotted against the acyl chain length for the tyrosol and hydroxytyrosol ester series, a parabolic shape with around 810 carbon atoms (caprylate and decanoate tyrosyl derivatives) indicating an adequate surfactant properties. Hence, these compounds could be considered as antioxidant surfactants. We can hypothesize that the antimicrobial and antileishmanial activities have a linear dependency to the surfactant property of a given tyrosyl

Table 3 Inhibitory spectrum of tyrosol (Ty) and tyrosyl esters on Gram-positive and Gram-negative bacteria

\begin{tabular}{|c|c|c|c|c|c|c|c|c|c|c|}
\hline \multirow[t]{2}{*}{ Strain } & \multirow[t]{2}{*}{ Gram } & \multicolumn{9}{|c|}{ Sensibility } \\
\hline & & Ty & $\mathrm{TyC}_{2}$ & $\mathrm{TyC}_{3}$ & $\mathrm{TyC}_{8}$ & $\mathrm{TyC}_{10}$ & $\mathrm{TyC}_{12}$ & $\mathrm{TyC}_{16}$ & $\mathrm{TyC}_{18}$ & $\mathrm{TyC}_{18: 1}$ \\
\hline Bacillus cereus & + & - & - & - & + & ++ & - & - & - & - \\
\hline Bacillus subtilis & + & - & - & - & - & - & - & - & - & - \\
\hline Micrococcus luteus & + & - & - & - & - & - & - & - & - & - \\
\hline Brevibacterium flavum & + & - & - & - & + & + & - & - & - & - \\
\hline Enterococcus faecalis & + & - & - & - & - & - & - & - & - & - \\
\hline Staphylococcus aureus & + & - & - & - & ++ & ++ & + & - & - & - \\
\hline Staphylococcus xylosus & + & - & - & - & ++ & ++ & + & - & - & - \\
\hline Staphylococcus epidermidis & + & - & - & - & - & - & - & - & - & - \\
\hline Pseudomonas aerigenosa & - & - & - & - & + & - & - & - & - & - \\
\hline Enterobacter cloacae & - & - & - & - & - & - & - & - & - & - \\
\hline Klebsielle pneumoniae & - & - & - & - & - & - & - & - & - & - \\
\hline Escherchia coli & - & - & - & - & - & - & - & - & - & - \\
\hline Salmonella & - & - & - & - & - & - & - & - & - & - \\
\hline
\end{tabular}

The bactericidal level was estimated by measuring the size of inhibition zone of the indicator strain. Insensitivity $(-)$, low sensitivity (+: Diameter of inhibition $<15$ $\mathrm{mm}$ ), high sensitivity (++: Diameter of inhibition between 15 et $20 \mathrm{~mm}$ ) 
Table 4 Minimum inhibitory concentrations (MIC) of Tyrosol (Ty) and Tyrosyl esters $\left(\mathrm{TyC}_{8}, \mathrm{TyC}_{10}\right.$ and $\left.\mathrm{TyC}_{12}\right)$ for three microbial strains after $24 \mathrm{~h}$ of incubation at $37^{\circ} \mathrm{C}$.

\begin{tabular}{|c|c|c|c|}
\hline \multirow[t]{2}{*}{ Compounds } & \multicolumn{3}{|c|}{ MIC $(\mu \mathrm{g} / \mathrm{mL})$} \\
\hline & S. aureus & S. xylosus & B.cereus \\
\hline Ty & ND & ND & $\mathrm{ND}$ \\
\hline $\mathrm{TyC}_{8}$ & 25 & 25 & 12.5 \\
\hline $\mathrm{TyC}_{10}$ & 12.5 & 12.5 & 3.1 \\
\hline $\mathrm{TyC}_{12}$ & 50 & 50 & $>100$ \\
\hline
\end{tabular}

derivative. Others [26] reported, in a study performed with cellular system (human fibroblasts), that the relationship of the interaction of the chlorogenic acid alkyl esters derivatives with biological membranes is quasiparabolic, which means that the efficiency of the interaction of such compounds with biological membranes raises concomitantly to the increase of their hydrophobic parts up to a certain length and then begins to diminish. This effect was described for the first time in 1939 when compiling a combination of studies related to an homologous series of compounds [27]. Sometimes named the parabolic case, this effect is now known under the name of cut-off effect. Others [28] reported that this effect is a general phenomenon observed in various biological and toxic activities with practically every amphiphilic homologous series tested so far.

In the light of these results, caprylate, capriate and laurate tyrosyl esters could be promising agents in transdermal therapeutic systems to control the drug release and cutaneous absorption as it was investigated by Cso'ka et al, [29] for sucrose fatty acid ester delivery. Indeed, these authors reported that among laurate, myristate, palmitate and stearate sucrose tested as drug delivery agents, only medium fatty acid chain length (sucrose laurate) increased the amount of released drug about 10 times.

\section{Conclusion}

Fatty acid with different chain lengths (from $C_{2}$ to $C_{18: 1}$ ) have been used to synthesize tyrosyl derivatives using Novozyme 435 in order to obtain a wide hydrophiliclipophilic phenolic compounds. From all the tested derivatives for their antimicrobial and antileishmanial activities, only medium chain derivatives $\left(\mathbf{T y C}_{\mathbf{8}}, \mathbf{T y C}_{\mathbf{1 0}}\right.$ and $\mathrm{TyC}_{\mathbf{1 2}}$ ) exhibited good antimicrobial and antileishmanial activities; maximum $\mathrm{MIC}$ and $\mathrm{IC}_{50}$ values are observed with $\mathbf{T y C}_{\mathbf{1 0}}$. These results open up potential applications to use medium tyrosyl derivatives surfactants, antioxidants, antimicrobial and antileishmanial compounds in cosmetic, food and pharmaceutical industries.

\section{Materials and methods \\ Materials}

Tyrosol and deuterated chloroform $\left(\mathrm{CDCl}_{3}\right)$ were purchased from Fluka (Switzerland), n-hexane from Prolabo (Paris, France) and ethyl acetate and proprionic acid from Pharmacia (Uppsala, Sweden). Caprylic, capric, palmitic and stearic, oleic acids and 2-methyl-2-propanol were purchased from Fluka (Germany). Lipase from Candida antarctica (Novozyme 435) was from Sigma Aldrish (Germany).

\section{Esterification reactions}

Production of tyrosyl acetate $\left(\mathrm{TyC}_{2}\right)$ was performed as previously reported by Aissa et al, [17]. Tyrosyl lipophilic esters $\left(\mathrm{TyC}_{3}\right.$ to $\left.\mathbf{T y C}_{\mathbf{1 8 : 1}}\right)$ were prepared by direct esterification of tyrosol by different fatty acids in screwcapped flasks. Tyrosol $(20 \mathrm{mg})$ was dissolved in $4 \mathrm{ml}$ equivalent volume ratio of 2-methyl-2-propanol/n-hexane. The fatty acid concentration was adjusted to obtain tyrosol/fatty acid molar ratio of eight. The mixture was stirred at $45^{\circ} \mathrm{C}$ in an orbital shaker at $200 \mathrm{rpm}$ and in the presence of $20 \mathrm{mg}$ of lipase. Control reactions in the absence of lipase were also realized. Aliquots from the mixture reaction were withdrawn at $72 \mathrm{~h}$ of incubation and filtered to be used for HPLC analysis. The conversion yield of tyrosyl derivatives was calculated as the ratio of number of moles of tyrosol converted per total number of tyrosol.

\section{HPLC Analysis}

The identification and the conversion yield of tyrosyl derivatives were carried out by HPLC analysis. It was performed using a Dionex apparatus composed of an LC-10ATvp pump and an SPD-10Avp detector. The column used is a C-18 $(4.6 \times 250 \mathrm{~mm}$; Shimpack VPODS), maintained at $35^{\circ} \mathrm{C}$. The flow rate used was 1.5

Table $5 \mathrm{IC}_{50}$ activities of tyrosol and its acyl chain derivatives against $L$. major and $L$. infantum parasite species evaluated by the MTT assay

\begin{tabular}{cccccccccc}
\hline Compounds & $\mathrm{Ty}$ & $\mathrm{TyC}_{2}$ & $\mathrm{TyC}_{3}$ & $\mathrm{TyC}_{8}$ & $\mathrm{TyC}_{10}$ & $\mathrm{TyC}_{12}$ & $\mathrm{TyC}_{16}$ & $\mathrm{TyC}_{18}$ & $\mathrm{TyC}_{18: 1}$ \\
\hline $\begin{array}{c}\mathrm{IC} 50(\mu \mathrm{g} / \mathrm{ml}) \\
\text { L. major }\end{array}$ & $\mathrm{ND}$ & $\mathrm{ND}$ & $\mathrm{ND}$ & 38.09 & 19.21 & 60.34 & $\mathrm{ND}$ & $\mathrm{ND}$ & $\mathrm{ND}$ \\
\hline $\begin{array}{c}\mathrm{IC} 50(\mu \mathrm{g} / \mathrm{ml}) \\
\text { L. infantum }\end{array}$ & $\mathrm{ND}$ & $\mathrm{ND}$ & $\mathrm{ND}$ & 62.8 & 38.73 & 157.6 & $\mathrm{ND}$ & & $\mathrm{ND}$ \\
\hline
\end{tabular}

* ND: Without effect up to $400 \mu \mathrm{g} / \mathrm{ml}$ 

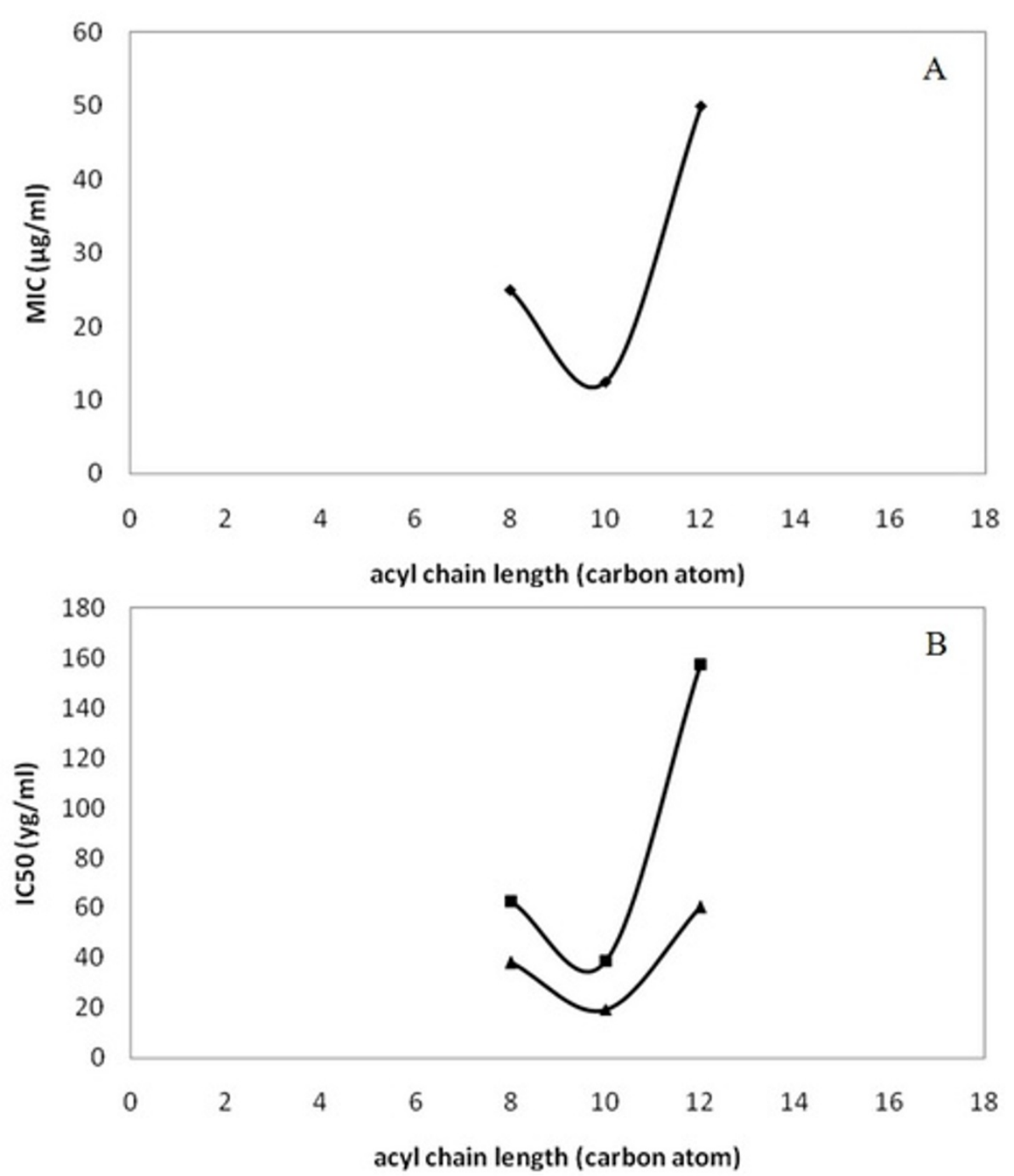

Figure 2 Acyl chain length of each tyrosyl derivatives plotted relatively to (A) MIC values obtained on staphylococcus strains (black diamonds) or to (B) IC 50 values obtained on L. major (black diamonds) or L. infantum (black triangle) parasites.

$\mathrm{mL} / \mathrm{min}$. The mobile phase used was $0.05 \%$ acetic acid in water (A) versus $0.1 \%$ acetic acid in acetonitrile (B) for a total running time of $20 \mathrm{~min}$ and the following proportions of solvent $\mathrm{B}$ were used for the elution: 0-3 min: $10-30 \%$; 3-5 min: $30-90 \%$; $5-18 \mathrm{~min}: 90 \%$ and $18-$ 20 min: $90-10 \%$.

\section{Purification and identification of Tyrosyl esters}

The reaction mixture resulting from the esterification of tyrosol with the different fatty acids contains a mixture of tyrosyl ester and residual substrates. After removal of the enzyme by centrifugation at $8000 \mathrm{rpm}$ for $15 \mathrm{~min}$, the mixture reaction was dried under nitrogen and 100 mg was taken up in $1 \mathrm{~mL}$ of Hexane. The purification of esters was achieved by chromatography on a silica gel 60 column (Merck) $(25 \mathrm{~cm} \times 2 \mathrm{~cm})$, previously equilibrated in hexane. Elution was carried using Hexane/Diethyl ether/acetic acid mixtures (50:48:2). The collected solvent fractions were analyzed by TLC using the same mobile phase. The color appeared through evaporated iodine. Purified fractions were pooled and solvents were evaporated at $40^{\circ} \mathrm{C}$ under vacuum.

NMR spectra were recorded on a Bruker A-300, spectrophotometer operating at $300 \mathrm{MHz}\left({ }^{1} \mathrm{H}\right)$ and 125,75 $\mathrm{MHz}\left({ }^{13} \mathrm{C}\right)$. For these experiments, samples were dissolved in deuterated chloroforme $\left(\mathrm{CDCL}_{3}\right)$ and obtained data are described in Tables 2 and 3.

\section{Antibacterial activity \\ Diffusion well method}

The bactericidal effects of tyrosol and its acyl esters were tested against several Gram positive and Gram 
negative bacteria on LB medium agar plate by agar spot assay [30]. The antibacterial activity was checked by well diffusion method [31]. Briefly, bacteria (previously preincubated $12 \mathrm{~h}$ in LB medium) were cultivated in LB medium at $37^{\circ} \mathrm{C}$ for $3 \mathrm{~h}$. A basal layer of LB containing $16 \mathrm{~g} / \mathrm{l}$ agar, was cooled in Petri dishes. When plates were dried, $10 \mathrm{ml}$ of soft LB ( $8 \mathrm{~g} / \mathrm{l}$ agar) containing $10^{7}$ cells were overlaid. Wells were then punched in the agar plate and filled with $20 \mu \mathrm{l}$ of each sample $(20 \mathrm{mg} /$ $\mathrm{ml}$ ). After $24 \mathrm{~h}$ of incubation at $37^{\circ} \mathrm{C}$, the zone of growth inhibition was measured to determine the level of bactericidal effect (Table 3).

Several bacteria strains were used: i.e., Staphyloccocus (S.) aureus, S. epidermidis, Bacillus (B.) cereus, B. subtilis, Micrococcus (M.) Luteus, Enterococcus (E.) faecalis, E. faecium, Enterobacter (E.) cloacae, Brevibacterium (B.) flavum, Pseudomonas (P.) Aeruginosa, Salmonella, Klebsielle (K.) pneumonia and Echerichia (E.) coli. Determination of the minimum inhibitory concentration (MIC)

The Minimal Inhibitory Concentrations (MICs) of tyrosol and its derivatives against the tested microorganisms were determined by the broth microdilution method [32]. All tests were performed in LB, supplemented with ethanol (with $0.2 \%$ as a highest final concentration). $S$. aureus, S. xylosus and B. cereus strains were cultured overnight at $37^{\circ} \mathrm{C}$ in LB. Test strains were suspended in LB (The initial absorbance measured at $600 \mathrm{~nm}$ was approximately adjusted to 0.2 Optical density (OD) value). Geometric dilutions ranging from $100 \mu \mathrm{g} / \mathrm{ml}$ to $1.5 \mu \mathrm{g} / \mathrm{ml}$ of $\mathbf{T y C}_{\mathbf{8}}, \mathbf{T y C}_{\mathbf{1 0}}$ and $\mathbf{T y C _ { 1 2 }}$ and $5 \mathrm{mg} / \mathrm{ml}$ to $0.625 \mathrm{mg} / \mathrm{ml}$ of tyrosol were prepared in 96-well microtiter plate, including one growth control (LB+ethanol). Plates were incubated under normal atmospheric conditions at $37^{\circ} \mathrm{C}$ for $24 \mathrm{~h}$. Absorbance was then measured at $600 \mathrm{~nm}$ and MICs values were determined as the lowest tyrosol derivatives'concentrations inhibiting visible growth of bacterial strains. Tests were performed in duplicates.

\section{Parasite culture}

L. major (MHOM/TN/95/GLC94 [23], and L. infantum (MHOM/TN/94/LV50 [24] strains isolated from Tunisian patients were used within this study. Promastigotes were cultured in solid medium at $26^{\circ} \mathrm{C}$, and then progressively adapted to a complete medium composed of RPMI 1640 and 10\% of Fetal Calf Serum (FCS). With a starting concentration of $3 \times 10^{6}$ parasites $/ \mathrm{ml}$, the stationary phase, where parasites are at their infective metacyclic forms, was reached after 6 days of culture.

\section{Parasite treatment}

Promastigote parasites were washed twice with RPMI 1640 , counted and dispatched at $10^{7}$ parasites/well in the complete medium. Parasites were then incubated for 24 $\mathrm{h}$ in the presence of serially diluted concentrations of tyrosyl derivatives (ranging from 3.125 to $400 \mu \mathrm{g} / \mathrm{ml}$ ). Negative controls correspond to parasites cultured in the absence of the tyrosyl derivatives and parasites with the elution buffer only. Tests were performed in duplicates.

\section{Leishmanicidal activity}

The effects of tyrosyl derivatives on Leishmania promastigotes were evaluated by the MTT assay as described by Dutta et al., [33]. After treatment with tyrosyl derivative solutions, microtitre plates were centrifuged at $1700 \mathrm{~g}$ for $10 \mathrm{~min}$ and supernatants were removed and replaced with the same volume of $1 \mathrm{mg} / \mathrm{ml}$ of MTT freshly dissolved in PBS. Plates were then incubated overnight at room temperature and centrifuged at $2500 \mathrm{~g}$. Formazan salt formed inside the parasite mitochondries was solubilized by discarding supernatants and adding SDS 10\% for $2 \mathrm{~h}$ at $37^{\circ} \mathrm{C}$ in the dark. Absorbance was measured at $540 \mathrm{~nm}$ using an ELISA plate reader. OD of each treated sample was compared to those grown without extracts. Each assay was performed in duplicate and independent experiments were realized at least twice.

\section{List of abbreviations}

$\mathrm{TyC}_{2}$ : Tyrosyl acetate; $\mathbf{T y C}_{\mathbf{3}}$ : Tyrosyl propionate; $\mathbf{T y C}_{\mathbf{8}}$ : Tyrosyl caprylate; TyC $_{10}$ : Tyrosyl capriate; $T_{y} C_{12}$ : Tyrosyl laurate; $T y C_{16}$ : Tyrosyl palmitate; TyC $_{18}$ : Tyrosyl stearate; TyC 18:1: Tyrosyl oleate; NMR: Nuclear magnetic resonance; $\mathbf{C D C L}_{\mathbf{3}}$ : deuterated chloroforme MIC: Minimum inhibitory concentration; $\mathbf{I C}_{50}$ : The half maximal inhibitory concentration; GLC94: Leishmania major; LV50: Leishmania infantum; FCS: Fetal Calf Serum; RPMI: Roswell Park Memorial Institute; MTT: bromure de 3-(4,5-dimethylthiazol-2yl)-2,5-diphenyl tetrazolium; PBS: phosphate buffered saline.

\section{Acknowledgements}

We are grateful to Mr. Adel Gargoubi and Ms. Lobna Jlail (CBS) for HPLC analysis, We are grateful to Pr. Sofiane Bezzine and Ms. Aida Karray (ENIS) for bacterial strains. This work received financial support from the Ministry of Higher Education, Scientific Research in Tunisia. Parasite experiments were partially supported by NIH/NIAID/DMID Grant Number 5P50AI074178 to LTCII.

\section{Author details}

${ }^{1}$ Laboratoire de Biochimie et de Génie Enzymatique des Lipases, Ecole Nationale d'Ingénieurs de Sfax (ENIS). Route de Soukra, BP 1173, 3038 Sfax, Université de Sfax,Tunisie. ${ }^{2}$ Groupe Immunobiologie des Leishmanioses, Labratoire de Transmission, Contrôle et Immunobiologie des Infections (LTCII), Institut Pasteur de Tunis, 13, place Pasteur, B.P 74, 1002 TunisBelvédère, Tunisie. 'ªboratoire des Bioprocédés, Centre de Biotechnologie de Sfax (CBS). BP 1177, 3018 Sfax, Université de Sfax, Tunisie.

\section{Authors' contributions}

IA carried out all the studies, analyzed the data and drafted the manuscript. RMS carried out the antileishmanial activity, MB: helped with the NMR analysis. DA and $\mathbf{S S}$ helped with the discussion of the data and the correction of the manuscript. YG participated in the study design and helped to draft the manuscript. All authors have read and approved the final manuscript.

\section{Competing interests}

The authors declare that they have no competing interests. 
Received: 16 December 2011 Accepted: 20 January 2012

Published: 20 January 2012

\section{References}

1. Shahidi F: Functional Foods: Their Role in Health Promotion and Disease Prevention. J Food Sci 2004, 69:146-149.

2. Ortega-Garcia F, Blanco S, Angeles Peinado M, Peragon J: Polyphenol oxidase and its relationship with oleuropein concentration in fruits and leaves of olive (Olea europaea) cv. 'Picual' trees during fruit ripening. Tree Physiol 2008, 28:45-54.

3. Cushnie TPT, Lamb AJ: Antimicrobial activity of flavonoids. Int J Antimicrob Agents 2005, 26:343-356.

4. Fki I, Allouche N, Sayadi S: The use of polyphenolic extract, purified hydroxytyrosol and 3, 4-dihydroxyphenyl acetic acid from olive mill wastewater for the stabilization of refined oils: a potential alternative to synthetic antioxidants. Food chem 2005, 93:197-204

5. Caruso D, Berra B, Giavarini F, Cortesi N, Fedeli E, Galli G: Effect of virgin olive oil compounds on in vitro oxidation of human low density lipoproteins. Nutr Metab Cardiovasc Dis 1999, 9:102-107.

6. De la Puerta R, Ruiz-Gutierrez V, Hoult JR: Inhibition of leukocyte 5lipoxygenase by phenolics from virgin olive oil. Biochem Pharmacol 1999, 57:445-449.

7. Giovannini C, Straface E, Modesti D, Coni E, Cantafora A, De Vincenzi M, Malorni W, Masella R: Tyrosol, the major olive oil biophenol, protects against oxidized LDL-induced injury in Caco2 cells. J Nutr 1999, 129:1269-1277.

8. Plotnikov MB, Chernysheva GA, Smol'yakova VI, Maslov MY, Cherkashina IV, Krysin AP, Sorokina IV, Tolstikova TG: Effect of $n$-tyrosol on blood viscosity and platelet aggregation. Bull Exp Biol Med 2007, 143:61-63.

9. Chernyshova GA, Plotnikov MB, Smol'yakova VI, Golubeva IV, Aliev OI, Tolstikova TG, Krysin AP, Sorokina IV: Antiarrhythmic activity of n-tyrosol during acute myocardial ischemia and reperfusion. Bull Exp Biol Med 2007, 143:689-691.

10. Vauzour D, Corona G, Spencer JPE: Caffeic acid, tyrosol and p-coumaric acid are potent inhibitors of 5-S-cysteinyl-dopamine induced neurotoxicity. Arch Biochem Biophys 2010, 501:106-111.

11. Fragopoulou E, Nomikos T, Karantonis HC, Apostolakis C, Pliakis E, Samiotaki M, Panayotou G, Antonopoulou S: J Agric Food Chem 2007, 55:80-89.

12. Mateos R, Espartero JL, Trujillo M, Rios JJ, Leon- Camacho M, Alcudia F, Cert A: Determination of phenols, flavones, and lignans in virgin olive oils by solid-phase extraction and high-performance liquid chromatography with diode array ultraviolet detection. J Agric Food Chem 2001, 49:2185-2192.

13. Yamaguchi T, Machida K, Kikuchi M: Analysis of the components of Ligustrum species. XVII. On the components of the flower of Ligustrum oValifolium Hassk. Annu Rep Tohoku Coll Pharm 1995, 42:105-107.

14. Acevedo L, Martinez E, Castaneda P, Franzblau S, Timmermann BN, Linares E, Bye R, Mata R: New phenylethanoids from Buddleja cordata. subsp. Cordata. Planta Med 2000, 66:257-261.

15. Bianco A, Melchioni C, Ramunno A, Romeo G, Uccella N: Phenolic components of Olea europaea-isolation of tyrosol derivatives. Nat Prod Res 2004, 18:29-32.

16. Oura S, Ashida Y, Kanamori Y, Oshima T, Mizutsu T, Kawato S, Suginami K, Abe $Y$ : Preparation of tyrosol esters and their use as lipid-metabolism enzyme inhibitors, preservatives, and reagents for biochemical research, JP-2003 026636.

17. Aissa I, Bouaziz M, Ghamgui H, Kammoun A, Miled N, Sayadi S, Gargouri Y Optimization of Lipase-Catalysed synthesis of acetylated tyrosol by response surface methodology. J Agric Food Chem 2007, 55:10298-10305.

18. Mateos R, Trujillo M, Pereira-Caro G, Madrona A, Cert A, Espartero JL: New lipophilic tyrosyl esters. Comparative antioxidant evaluation with hydroxytyrosyl esters. J Agric Food Chem 2008, 56:10960-10966.

19. Ahn EY, Jiang $Y$, Zhang $Y$, Son EM, You S, Kang S, Park JS, Jun JH, Lee BJ, Kimi DKY: Cytotoxicity of $p$-tyrosol and its derivatives may correlate with the inhibition of DNA replication initiation. Oncol Rep 2008, 19:527-534.

20. Singh IP, Jain SK, Kaur A, Singh S, Kumar R, Garg P, Sharma SS, Arora SK Synthesis and Antileishmanial activity of Piperoyl-Amino Acid Conjugates. Eur J Med Chem 2010, 45:3439-3445.
21. Coulon D, Girardin M, Rovel B, Ghoul M: Comparison of direct esterification and transesterification of fructose by Candida antartica lipase. Biotech Lett 1995, 2:183-186.

22. Selmi B, Gontier E, Ergan F, Thomas D: Effects of fatty acid chain length and unsaturation number on triglyceride synthesis catalyzed by immobilized lipase in solvent-free medium. Enz Microb Technol 1998, 23:182-186.

23. Kebaier C, Louzir H, Chenik M, Ben Salah A, Dellagi K: Heterogeneity of wild Leishmania major isolates in experimental murine pathogenicity and specific immune response. Infect Immun 2001, 69:4906-4915.

24. Aoun K, Bouratbine A, Harrat Z, Belkaied M, Bel hadj Ali S: Particular profile of the zymodemes of Leishmania infantum causing visceral leishmaniasis in Tunisia. Bull Soc Patho Exot 2001, 94:375-377.

25. Lucas R, Comelles F, Alcantra D, Maldonado OS, Curcuroze M, Parra JL, Morales JC: Surface-Active Properties of Lipophilic Antioxidants Tyrosol and Hydroxytyrosol Fatty Acid Esters: A Potential Explanation for the Nonlinear Hypothesis of the Antioxidant Activity in Oil-in-Water Emulsions. J Agric Food Chem 2010, 58:8021-8026.

26. Laguerre M, LopezGiraldo LJ, Lecomte J, Figueroa-Espinoza MC, Barea B, Weiss J, Decker EA, Villeneuve P: Chain length affects antioxidant properties of chlorogenate esters in emulsion: The cutoff theory behind the polar paradox. J Agric Food Chem 2009, 57:11335-11342.

27. Ferguson $\mathrm{J}$ : The uses of chemical potentials as indices of toxicity. Proc $R$ Soc London, Ser B 1939, 127:387-404.

28. Balgavy P, Devinsky F: Cut-off effects in biological activities of surfactants Adv Colloid Interface Sci 1996, 66:23-63.

29. Cso'ka G, Marton S, Zelko R, Otomo N, Antal I: Application of sucrose fatty acid esters in transdermal therapeutic systems. Eur j Pharm Biopharm 2007, 65:233-237.

30. Paik HD, Bae SS, Park SH, Pan JG: Identification and partial characterisation of tochicin, a bacteriocin produced by Bacillus thuringiensis subsp. tochigiensis. J Ind Microbiol Biotech 1997, 19:294-298.

31. Jack RW, Tagg JR, Ray B: Bacteriocins of Gram positive bacteria. Microbio Rev 1995, 59:171-200.

32. NCCLS: Performance standards for antimicrobial disk susceptibility testing 1997. National Committee for Clinical Laboratory Standards, 6th International Supplement, Wayne Pa. M2-A6.

33. Dutta A, Bandyopadhyay S, Mandal C, Chatterjee M: Development of a modified MTT assay for screening antimonial resistant field isolates of Indian visceral Leishmaniasis. Parasito Int 2005, 54:119-122.

doi:10.1186/1476-511X-11-13

Cite this article as: Aissa et al:: Synthesis of lipophilic tyrosyl esters derivatives and assessment of their antimicrobial and antileishmania activities. Lipids in Health and Disease 2012 11:13.

\section{Submit your next manuscript to BioMed Central and take full advantage of:}

- Convenient online submission

- Thorough peer review

- No space constraints or color figure charges

- Immediate publication on acceptance

- Inclusion in PubMed, CAS, Scopus and Google Scholar

- Research which is freely available for redistribution

Submit your manuscript at www.biomedcentral.com/submit
C Biomed Central 